\title{
Characterization of Banana Peels Wastes as Potential Slow Pyrolysis Feedstock
}

\author{
Isa Kabenge ${ }^{1}$, Godfrey Omulo ${ }^{1}$, Noble Banadda ${ }^{1,2}$, Jeffrey Seay ${ }^{3}$, Ahamada Zziwa ${ }^{1} \&$ Nicholas Kiggundu ${ }^{1}$ \\ ${ }^{1}$ Department of Agricultural and Biosystems Engineering, Makerere University, Kampala, Uganda \\ ${ }^{2}$ Department of Agricultural and Biosystems Engineering, Iowa State University, Ames, USA \\ ${ }^{3}$ Department of Chemical Engineering, University of Kentucky College of Engineering, Paducah Extended \\ Campus Program, Paducah, USA
}

Correspondence: Isa Kabenge, Department of Agricultural and Biosystems Engineering, Makerere University, P.O. Box 7062, Kampala, Uganda. Tel: 256-7-7237-7172, E-mail: isakabenge@gmail.com
Received: October 30, 2017
Accepted: January 24, 2018 Online Published: March 30, 2018
doi:10.5539/jsd.v11n2p14
URL: https://doi.org/10.5539/jsd.v11n2p14

\begin{abstract}
Uganda is the world's second largest producer and consumer of banana after India. This has resulted into vast quantities of banana wastes, including the leaves, pseudostem, stalks, rejected and rotten fruits and the fruit peels. This study focuses on the characterization of banana peels to yield banana peels vinegar (BPV), tar and biochar as value added products that can be useful to farmers. Dried banana peels were characterized via proximate, ultimate, lignocellulosic, thermogravimetric (TG), and calorific value analyses. The obtained results showed that the volatile matter and fixed carbon contents were $88.02 \%$ and $2.70 \%$ while carbon, nitrogen and sulphur were $35.65 \%, 1.94 \%$ and $20.75 \mathrm{ppm}$ respectively. The hemicellulose, cellulose and lignin contents were $41.38 \%, 9.90 \%$ and $8.90 \%$ while the higher and lower heating values were $16.15 \mathrm{MJ} / \mathrm{kg}$ and $14.80 \mathrm{MJ} / \mathrm{kg}$. The maximum devolatilization rate in the banana peel biomass occurred in the temperatures range of $450-550^{\circ} \mathrm{C}$ which was taken as the slow pyrolysis regime temperature. The high levels of fixed carbon, volatile matter and ash contents were strong indicators that banana wastes are adequate feedstock for pyrolysis work to yield bio-infrastructure products. Similarly, the lignin, cellulose and hemicellulose fractions had significant correlation between the biomass heating values and the eventual chemical compounds present BPV and biochar. The characterization properties of the banana peels are akin to the leaves and pseudostem and thus are suitable for pyrolysis process.
\end{abstract}

Keywords: banana peels, bio-infrastructure products, characterization, heating values, value-added products

\section{Introduction}

Banana production in Uganda is very high since it is the world's second largest producer and consumer of banana after India (Uganda Bureau of Statistics[UBoS], 2014). According to Food and Agriculture Organization of United Nations[FAO], (2013), the average annual production of banana and plantain in Uganda is approximated at $4,375,000$ metric tonnes. Banana plantations occupy $17 \%$ of the total agricultural land, $9,115,180$ ha (Omulo, Banadda, \& Kiggundu, 2015). Although, the production of banana in Uganda varies by region, Omulo et al. (2015) noted that all the regions of the country produce substantial amounts (错误!未找到 引用源。) that can be used. According to UBoS (Uganda Bureau of Statistics, 2014), western region contributes the greatest percentage of banana produced, 2,883,648 tonnes, followed by the central region at 1,039,837 tonnes, the eastern region at 342,234 tonnes and the northern region producing 31,626 tonnes annually. As a result, of this vast production of banana in Uganda, large quantities of banana wastes, including the leaves, pseudostem, stalks, rejected and rotten fruits and the fruit peels are generated yearly but without any value addition.

According to Fernandes, Marangoni, Souza, and Sellin (2013), for every single tonne of bananas harvested, there are on average four tonnes of lignocellulosic wastes including three tonnes of pseudostem, $480 \mathrm{~kg}$ leaves, $440 \mathrm{~kg}$ banana peels and $160 \mathrm{~kg}$ stalks as well as $100 \mathrm{~kg}$ of rotten fruits. In Uganda this translates to about 17,500,000 tons of banana wastes annually. Currently, these wastes are mostly spread over the fields and left to decompose with time to improve soil fertility. Similarly, only small amounts of the banana fruit peels are utilized as animal feeds by farmers as well as for biogas digestion feedstock especially for experimental purposes. Therefore, the banana wastes contribute greatly to environmental pollution and soil degradation since no feasible utilization has 
been employed. The present efforts used to harness the banana biomass as fuels and soil conditioners are very traditional and inefficient, this has in turn resulted to high levels of pollutions and land degradation (Okello, Pindozzi, Faugno, \& Boccia, 2013). This is a major concern since in the recent past undesirable alterations in biodiversity; water resources and soil degradation have been witnessed in Uganda.

Banana leaves and stem wastes have been characterized as a feedstock for slow pyrolysis process to yield bio-oil and biochar by Fernandes et al. (2012) in Brazil. However, no published studies have been conducted on characterization of banana peel wastes for slow pyrolysis. The ultimate, proximate, lignocellulosic and calorific value analyses as well as the thermogravimetric analysis are very crucial while determining the potential of biomass as a pyrolysis feedstock. The heating value (calorific value) is a very crucial distinguishing factor in the design calculations and simulation of numerical thermal systems for biomass (Fernandes et al., 2013). Similarly, the thermogravimetric analysis of biomass is paramount in knowing the temperature regimes with highest weight degradation rates and thus pyrolysis temperature required (Chaiwong, Kiatsiriroat, Vorayos, \& Thararax, 2013; Biswas et al., 2016). Therefore, the main objective of this study was to characterize banana peels wastes as a potential of slow pyrolysis feedstock to yield vinegar, tar and biochar. In the same vein, the research was aimed at improving resource recovery from banana plants as a means of curbing environmental pollution as well as a potential source of biofuels and bioenergy for Uganda.

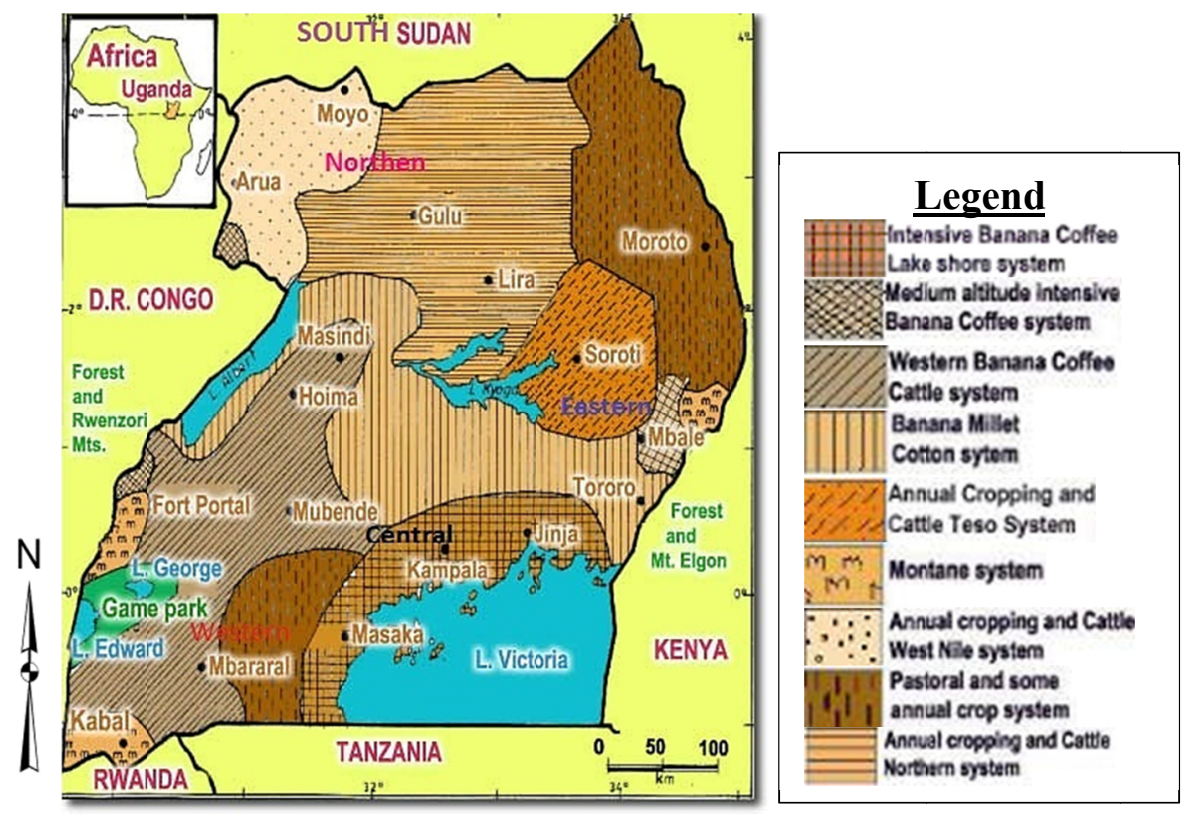

Figure 1. A map showing farming system in Uganda with interest in banana growing areas

Source: (Omulo et al., 2015)

\section{Materials and Methods}

\subsection{Materials Source and Preparation}

This study was carried out in agricultural engineering workshop at Makerere University Agricultural Research Institute Kabanyolo (MUARIK), Uganda. The location of institute is at latitude $0.45^{\circ}$ and longitude $32.62^{\circ}$ in Wakiso district approximately $21 \mathrm{~km}$ north of Kampala city. The study utilized the available banana pseudostem and leaf wastes from the agricultural banana farm but narrowing down to mpologoma, kisansa and kibuzi banana species. The wet banana peels were solely obtained from the institute's canteen kitchen.

The initial moisture contents of the fresh banana wastes were determined using the Inspector Pro moisture and humidity meter. The probe pin was inserted into the fresh biomasses and moisture content measurements were displayed instantly. The samples were then cut into small pieces $(5.0 \mathrm{~mm})$ to increase the surface area for drying and then thoroughly washed in clean water to eradicate dirt and organic matter. At first the samples were air dried for three days while the approximate moisture contents were checked by air-drying $50 \mathrm{~g}$ of the samples and weighing at an interval of 24 hours until insignificant weight loss was obtained (Selvarajoo \& Hanson, 2014). However, due to weather variations the remainder of the banana wastes samples were put in an oven at $100^{\circ} \mathrm{C}$ for 24 hours to dry up to a moisture content of about 5-6\% prior to grinding (Soetardji, Widjaja, Djojorahardjo, 
Soetaredjo, \& Ismadji, 2014). Finally, the dried banana samples were ground to smaller particle sizes using hammer mill (Brook Crompton series $2000 \mathrm{Model}$ ) and a sieve size of $2.5 \mathrm{~mm}$ suitable for characterization and thermogravimetric analysis (Yoder, Galinato, Granatstein, \& Garcia-Pérez, 2011).

\subsection{Feedstock Characterization}

\subsubsection{Proximate Analysis}

The moisture content was determined using the oven dry method. Clean dishes were placed in a drying oven at $105^{\circ} \mathrm{C}$ for one hour to dry then transferred into a desiccator until they cooled. Their individual weights were noted and about $2 \mathrm{~g}$ of each banana waste sample was added and reweighed accurately while noting the weights. The dishes with the samples were then placed in a drying oven at $105^{\circ} \mathrm{C}$ for 12 hours. The dishes with the dried samples were removed from the oven, placed in a desiccator until they cooled and then individually weighed. The loss in weight was reported as the moisture content as given by Equation 1 while the dry matter content was established by subtracting moisture content from the whole fraction $(100 \%)$.

$$
\text { Moisture content }(\%)=\left(\frac{W_{m}-W_{d}}{W_{m}}\right) \times 100
$$

Where: $W_{m}=$ Initial sample weight, $W_{d}=$ Final dried sample weight

Similarly, the ash, volatile solids and fixed carbon contents were determined using muffle furnace ashing method. First, three porcelain crucibles were carefully ignited over a muffle furnace using tongs for a few minutes. They were then cooled in desiccator and weighed; afterwards about $2 \mathrm{~g}$ of the samples were weighed and put into each crucible. They were then put in the muffle furnace set at $600^{\circ} \mathrm{C}$ and maintained at this temperature for three hours with the help of an automatic control pyrometer. Finally, using tongs the crucibles were transferred directly into a desiccator to cool then weighed immediately. The percentage ash content for each sample was calculated as given by Equation 2 .

$$
\text { Ash content }(\%)=\left(\frac{W_{c a}-W_{c}}{W_{s}}\right) \times 100
$$

Where: $W_{c a}=$ weight of the crucible and ash, $W_{c}=$ weight of crucible and $W_{s}=$ weight of the sample.

Likewise, during the burning, the total fixed solids residues that remained after ignition at $550^{\circ} \mathrm{C}$ for 15 minutes were weighed and noted as the volatile solids matter lost. The fixed carbon content was established by the difference between the total sample mass and sum of the ash and volatile contents. These experiments were carried out in triplicates.

\subsubsection{Ultimate Analysis}

Nitrogen contents were determined by calometric method using a block digester (BUCHI digest system K-437 model). A digest was obtained by treating the biomass samples with hydrogen peroxide, sulphuric acid, selenium and salicylic acid. This principle took into account the possible ommission of nitrates by coupling them with salicylic acid in an acid mediatoform 3-nitrosalicylic and or 4-nitrosalicylic. The compounds were then reduced to their corresponding amino acid forms by the organic matter in the samples since the analysis of total nutrients required complete oxidation of organic matter. The hydrogen peroxide oxidised the organic matter while the selenium compound acted as catalyst in the process. Addition of $30 \% \mathrm{H}_{2} \mathrm{SO}_{4}$ completed the digestion at elevated temperatures.

The entire digest was then diluted with the blanks to a ratio of 1:9 (v/v) with distilled water to match the standards. With a micropipette, $0.2 \mathrm{ml}$ of the sample digest was taken and added to $5.0 \mathrm{ml}$ of the reagent $\mathrm{N}_{1}$, vortex and $5.0 \mathrm{ml}$ reagent $\mathrm{N}_{2}$, vortex. They were allowed to stand for two hours and the absorbency measured by spectrophotometer at $650 \mathrm{~nm}$. The blue color was stable for atleast 10 hours and a plot of calibration curve and concentartion of nitrogen were read off. The nitrogen concentration in the sample material expressed in $\% \mathrm{~N}$ was calculated as given by Equation 3 .

$$
N \%=\frac{(a-b) \times v \times 100}{1000 \times w \times a l \times 1000}
$$

Where: $a=$ concentration of $\mathrm{N}$ in the solution, $b=$ concentarion of $\mathrm{N}$ in the blank, $v=$ total volume at the end of analysis procedure, $w=$ weight of the dried sample and $a l=$ aliquot of the solution taken.

On the other hand, the carbon, hydrogen and sulphur contents analyses were carried out using ULTRA CHS-580 elemental analyzer. ULTRA CHS-580 analyzer resistance furnace had a horizontal orientation and utilized 
oxygen gas of purity of $99.5 \%$ to heat upto $1550^{\circ} \mathrm{C}$ at steps of $1{ }^{\circ} \mathrm{C}$. The samples were homogenized and then weighed by electronic balance to weights ranging between $250-500 \mathrm{mg}$. The values of the weights were then input to the PC system manually before the ceramic boats fed into the combustion chamber of the furnace using tongs. The analyzer used a solid state infrared absorption detection method with three independent infrared cells. The analysis time ranged between 74-115 seconds during which the detector signals were plotted automatically on the PC screen. The experiments were run in triplicates for the three banana waste samples. The results and graphs generated were tranfered to MS word pages for intepration.

\subsubsection{Chemical Analysis}

Lignocellulosic fractions (cellulose, hemicellulose and lignin) of the banana waste samples were investigated by the Van-Soest and Wine methodology (Van-Soest \& Wine, 1968) and the refluxing apparatus procedures. This was done using two analytical methods: neutral-detergent fibre (NDF) (Equation 4) and acid detergent fibre (ADF). NDF analyzed the total fibre in the samples, that is, the residue that remains after treatment of the biomass with neutral detergent solution (sodium lauryl sulphate and EDTA).

On the other hand, ADF dealt with the lignocellulose determination whereby the residues that remained after treatment with acid detergent solution were oxidized by Cetyl trimethylammonium bromide in $\mathrm{H}_{2} \mathrm{SO}_{4}$ solution . The difference between the ADF and NDF was interpreted as the hemicellulose content (Saikia, Chutia, Kataki, \& Pant, 2015). The mass difference between the banana peels samples digested with acid detergent $\left(72 \% \mathrm{H}_{2} \mathrm{SO}_{4}\right)$ followed by an oxidation by buffered solution of acetic acid together with potassium permanganate was taken as the lignin content (Pérez-Hidalgo, Guerra-Hernández, \& García-Villanova, 1997). Similarly, the cellulose contents were established by determining the mass difference of the dry sample residues which resulted from the lignin content analysis after putting them in a muffle furnace set at a temperature of $500-550^{\circ} \mathrm{C}$ for a period of three hours (Vardon, Sharma, Blazina, Rajagopalan, \& Strathmann, 2012). Equations 5-7 illustrate ash, lignin and cellulose contents determination. These three analyses were done in triplicates for a period of three days.

$$
\operatorname{NDF}(\%)=\frac{\left(W_{2}+C_{1}\right)-\left(W_{3}+C_{2}\right)}{W 1 \times D M \%} \times 100
$$

Where: $W_{1}=$ weight of sample, $W_{2}=$ weight of crucible + fibre, $W_{3}=$ weight of crucible + ash, $C_{l}=$ correction for $W_{2}$ read from the balance (due to hot weighing) and $C_{2}=$ correction for $W_{3}$ read from the balance (due to hot weighing)

$$
\begin{aligned}
& \text { Ash contained in } \operatorname{ADF}_{(\%)}=\frac{\left(W_{3}+C_{2}\right)-\left(W_{5}+C_{4}\right)}{W_{1} \times D M \%} \times 100 \\
& \quad \text { Lignin content }(\%)=\frac{\left(W_{4}+C_{3}\right)-\left(W_{5}+C_{4}\right)}{W_{1} \times D M \%} \times 100 \\
& \text { Cellulose content }(A D F-A s h \%)=\frac{\left(W_{5}+C_{4}\right)-\left(W_{2}+C_{1}\right)}{W_{1} \times D M \%} \times 100
\end{aligned}
$$

Where: $W_{1}=$ weight of air-dried sample, $W_{2}=$ weight of empty crucible, $W_{3}=$ weight of crucible $+\mathrm{ADF}, W_{4}=$ weight of crucible + lignin + ash and $W_{5}=$ weight of crucible + ash.

Therefore, the hemicellulose, cellulose and lignin contents as described by Van-Soest and Wine (Van-Soest \& Wine, 1968) methods is summarized as:

- $\quad$ Hemicellulose $=\mathrm{NDF}-\mathrm{ADF}$

- $\quad$ Lignin $=\mathrm{ADL}$

- $\quad$ Cellulose $=\mathrm{NDF}-($ Hemicellulose + Lignin $)$

Where: NDF $=$ Neutral Detergent Fibre, ADF $=$ Acid Detergent Fibre, and ADL = Acid Detergent Lignin.

\subsubsection{Calorific Value Analysis}

The calorimetric experiment was carried out using a Bomb Calorimeter (Ika 2000 Basic Model). The calorimeter ensured combustion of the biomass samples (banana wastes) under precisely defined conditions, in the measuring cell. The components of measuring cell included an inner vessel with insulating water jacket (outer vessel) and a stirrer which ensured uniform distribution of heat in the inner vessel. In addition, it included a water circuit with a heating element, automatic filling, a temperature sensor and an oxygen filling apparatus for the decomposition vessel.

The banana biomass samples were formed into small briquettes using a briquette machine in weight range of 
0.8-1.1 g. The calorimeter was given six minutes to stabilize before the briquettes were fed carefully put beneath the firing string in the crucible. After calibration, the measuring cell cover closed automatically and the decomposition vessel immersed with the sample in the inner vessel. Pure oxygen (99.95\%) was introduced until a pressure of 30 bars was reached.

The briquette fuel sample ignited electrically within the ignition device and the increase in temperature of the water in the inner vessel was measured leading to determination of the high heating value (HHV). This was displayed on the control panel screen as a graph and a numerical value for the HHV of the sample fed. This procedure was repeated three times for the individual banana samples. The HHV determined were confirmed using the Luo and Resende (2014) principle which incorporates individual elemental percentages from ultimate analysis data (Equation 8).

$$
H H V(M J / k g)=\% C \times 0.3578+\% H \times 1.1356+\% N \times 0.0594-\% O \times 0.0854-0.974
$$

The lower heating values (LHV) of the samples were determined using the higher heating values (HHV) and hydrogen contents according to Abdullah, Sulaiman, Miskam, \& Taib (2014) as described by Equation 9.

$$
L H V_{d r y}=H H V_{d r y}-2.442 \times(8.936 H / 100) \quad M J / k g
$$

\subsubsection{Thermal Analysis}

Thermo-gravimetric analysis of the banana biomass wastes was conducted using the Eltra Thermostat TGA 1.4.2.12 model. Banana biomass samples were introduced manually into the TGA after being weighed by the integrated detection balance at $1.100 \pm 0.05 \mathrm{~g}$ and then put into 12 crucibles containing four replicates of the three samples. The average weight of the samples fed were $1.642 \mathrm{~g}, 1.1577 \mathrm{~g}$ and $1.1572 \mathrm{~g}$ of peels, leaves, pseudostems, respectively. The samples were fed to the analyzer by an external autoloader and were ejected after the measurement, allowing for a high throughput. The resistance heated ceramic furnace programmed in $1^{\circ} \mathrm{C}$ was heated from $50^{\circ} \mathrm{C}$ to a maximum temperature of $900^{\circ} \mathrm{C}$ at a gas flow rate of $70 \mathrm{ml} / \mathrm{min}$ and at a heating rate of $15^{\circ} \mathrm{C} / \mathrm{min}$. The samples were characterized by thermal decomposition curves (under $\mathrm{N}_{2}$ flow) and combustion curves (under $\mathrm{O}_{2}$ flow). The process was controlled via computer standard SOP software to investigate various thermogravimetric parameters. The experiment was run for a period of four hours and the curve plots for rise in temperature, percentage weight loss and first derivative (rate) of the weight loss were plotted and displayed on the computer monitor.

\section{Results and Discussions}

\subsection{Characterization of Banana Wastes Biomasses}

The initial moisture content levels of the fresh banana biomass wastes collected from the farm at MUARIK were averagely high as $87 \%, 78 \%$ and $72 \%$ for the pseudostem, leaves and the peels, respectively. However, after oven drying and size reduction, the proximate, ultimate, chemical analyses were done and the findings noted as discussed below.

\subsubsection{Proximate Analysis}

Table 1 shows the proximate analysis values of the banana biomass wastes. The values were presented as percentage dry basis. There was significant difference in the moisture content, volatile matter content and fixed carbon results while there was no significant difference in the values of ash content for the three samples.

Table 1. Proximate analysis results of banana biomass wastes

\begin{tabular}{lrrrr}
\hline & Peels & Leaves & Pseudostem & $p$-value \\
Proximate Analysis & ${ }^{*}$ wt.\% & wt.\% & wt.\% & \\
\hline Moisture Content & $11.56^{\mathrm{a}} \pm 0.06$ & $6.67^{\mathrm{b}} \pm 0.08$ & $7.98^{\mathrm{c}} \pm 0.17$ & 0.000 \\
Volatile Matter Content & $88.02^{\mathrm{a}} \pm 1.33$ & $83.35^{\mathrm{a}} \pm 2.10$ & $89.43^{\mathrm{b}} \pm 0.78$ & 0.006 \\
**Fixed Carbon Content & $2.70^{\mathrm{a}} \pm 0.78$ & $7.60^{\mathrm{b}} \pm 1.19$ & $1.21^{\mathrm{a}, \mathrm{b}} \pm 0.61$ & 0.004 \\
Ash Content & $9.28^{\mathrm{a}} \pm 0.22$ & $9.05^{\mathrm{a}} \pm 0.28$ & $9.36^{\mathrm{a}} \pm 0.44$ & 0.515 \\
\hline
\end{tabular}

Note. ${ }^{*}$ wt. $\%$ - Percentage weight, $* *$ Determined by difference $=100$ - (Volatile matter + Ash Content)

${ }^{a}$ Means not labeled with letter (a) are significantly different from control level mean 
The moisture content levels of the dried samples ranged between 6.7 to $11.6 \%$ which is acceptable for pyrolysis requirements of biomass because biomass with higher moisture content requires more thermal energy to vaporize the contained water in the thermochemical conversion (Fernandes et al., 2012). Similarly, bio-oil yields from biomasses with high moisture contents tend to have high moisture content which impacts negatively on the fuel energy values (HHV) and overalls pyrolysis process efficiency (Sait, Hussain, Salema, \& Ani, 2012 and Fernandes et al., 2013). Conversely, high values of volatile matter content of $88.02 \%, 83.35 \%$ and $89.43 \%$ for peels, leaves and pseudostem, respectively were recorded. This signified the possibility of a high organic load, a high susceptibility to thermal degradation status and a high bio-oil potential of the banana wastes biomass (Saidur, Abdelaziz, Demirbas, Hossain, \& Mekhilef, 2011; Sait et al., 2012; Fernandes et al., 2012; Montoya et al., 2014 and Plis et al., 2015). The fixed carbon contents for the banana peels, leaves and pseudostem were $2.7 \%$, $7.6 \%$ and $1.21 \%$, respectively, thus showing that banana leaves have the highest amounts of fixed carbon content. This corresponds to results of some prior works on non-woody biomasses like radiata pine $4.38 \%$ (Moore, Park, Segura, \& Carrier, 2015), baltic sea green algae 5.1\% (Plis et al., 2015), banana fruit bunch $0.2 \%$ (Abdullah et al., 2014), and sugar cane straw 6.7-8.3\% (Fernandes et al., 2013 and Montoya et al., 2014). High fixed carbon contents are strong indicators of the banana wastes biomass suitability for thermochemical conversion processes like pyrolysis (Fernandes et al., 2013). This was true similarly due to the high calorific values (Doumer et al., 2015). The ash contents were approximately $9 \%$ which was ideal since according to Fernandes et al. (2013) biomasses with higher ash contents above $20 \%$ are not good energy converters. Therefore, low ash and high volatile matter content biomasses are the best feedstock for bioenergy conversion including pyrolysis and gasification processes among others (Maiaa et al., 2014 and Jourabchi et al., 2014).

\subsubsection{Ultimate Analysis}

The values recorded from ultimate analysis are presented in 错误!未找到引用源。. The carbon contents of the three biomasses were ideal with the leaves having the highest as $38.57 \%$ while hydrogen contents were averagely $6 \%$. Nitrogen content was highest in the leaves while oxygen at (49.94\%) and sulphur at $(0.04 \%)$ were notably high in the pseudostem. The ash contents $(9 \%)$ were generally similar in the three biomasses. The low ash content is an advantage since biomass with ash content yields of over $20 \%$ are not fit for heat generation and can lead to fouling during the operations (Fernandes et al., 2013). These values compared well with the previous studies carried out (Saidur et al. (2011), Fernandes et al. (2013), Pighinelli, Boateng, Mullen, \& Elkasabi (2014) and Abdullah et al. (2014)) which noted that the expected elemental percentage range in a lignocellulosic biomass are as follows: carbon to be between $35-54 \%$, hydrogen $4.5-9 \%$, oxygen $40-48 \%$, nitrogen less than $3 \%$ and sulfur less than $1 \%$.

Table 2. The Elemental Analysis percentages of banana biomass wastes

\begin{tabular}{lrrrr}
\hline Elements (\%) & Peels & Leaves & Pseudostem & $p$-value \\
\hline Carbon & $35.65^{\mathrm{a}} \pm 0.21$ & $38.57^{\mathrm{b}} \pm 0.17$ & $33.46^{\mathrm{c}} \pm 0.36$ & 0.000 \\
Hydrogen & $6.19^{\mathrm{a}} \pm 0.07$ & $6.44^{\mathrm{a}} \pm 0.25$ & $6.44^{\mathrm{a}} \pm 0.23$ & 0.118 \\
Nitrogen & $1.94^{\mathrm{a}} \pm 0.16$ & $2.45^{\mathrm{b}} \pm 0.07$ & $0.80^{\mathrm{c}} \pm 0.02$ & 0.000 \\
* Oxygen & $45.94^{\mathrm{a}} \pm 0.17$ & $43.49^{\mathrm{b}} \pm 0.19$ & $49.94^{\mathrm{c}} \pm 0.26$ & 0.000 \\
Sulphur & $20.75^{\mathrm{a}} \pm 9.55 \mathrm{ppm}$ & $32.70^{\mathrm{b}} \pm 5.09 \mathrm{ppm}$ & $0.04^{\mathrm{a}, \mathrm{b}} \pm 0.004$ & 0.000 \\
Ash & $9.28^{\mathrm{a}} \pm 0.22$ & $9.05^{\mathrm{a}} \pm 0.28$ & $9.36^{\mathrm{a}} \pm 0.44$ & 0.514 \\
C:N ratio & 18.38 & 15.74 & 41.83 & - \\
Organic Matter & 58.08 & 60.61 & 61.20 & -
\end{tabular}

Note. ${ }^{*}$ Oxygen was calculated by difference $=100-($ Carbon + Hydrogen + Nitrogen $)$

${ }^{a}$ Means not labeled with letter (a) are significantly different from control level mean

According to Fernandes et al. (2013) ultimate analysis is critical in determining the biomass fuel potential, calorific values and the expected environmental impact. The presence of elements like carbon, hydrogen, nitrogen and oxygen influenced highly the heating values while on the other hand higher values of elements like $\mathrm{N}, \mathrm{S}$ and $\mathrm{Cl}$ were strong pointers to likelihood of negative environmental effects and corrosions from the biomass fuels. Similarly, the presence of $\mathrm{N}$ in the biomass was an indicator that their biochars were suitable 
ingredients for soil fertility enhancement for crop production (Doumer et al., 2015). The high percentage of ash similarly indicates the possibility of heavy elements thus characterization before use is of essence.

\subsubsection{Lignocellulosic Analysis}

Lignocellulosic fraction refers to a mixture of the lignin, cellulose and hemicellulose fractions. This whole fraction is equivalent to approximately half of the total plant material generated via photosynthesis process thus the largest source of renewable organic energy (Saidur et al., 2011). Typically, cellulose forms the biggest proportion of the fraction then the hemicellulose and lignin, respectively. Consequently, cellulose and hemicellulose are termed as macromolecule polysaccharides made from various sugars and utilized in ethanol production while lignin are scented polymers which are manufactured from antecedent phenylpropaniods (Xu, Wang, \& Cheng, 2011 and Saidur et al., 2011).

The lignocellulosic fractions (Table 3 ) revealed that hemicellulose was generally high in the peels $(41.38 \%)$ while cellulose and lignin were remarkably high in pseudostem $(38.48 \%)$ and leaves $(10.58 \%)$ respectively. There was significant difference in the values of hemicellulose, cellulose and lignin contents for the three banana biomass samples. The amount of lignin in lignocellulosic biomass depicted the association with biomass heating value (Saidur et al., 2011). From the banana biomass wastes, lignin influenced the high heating values more than the cellulose and hemicellulose as can be noted from the calorific values in Table 4. Thus, the high lignin content of the banana leaves $(10.58 \%)$ contributed to the HHV recorded. The hemicellulose, cellulose and lignin contents were analogous to other types of biomass like sugarcane bagasse, sugarcane straw, rice husk, soft woods and elephant grass among others (Montoya et al., 2014; Fernandes et al., 2013).

Table 3. Lignocellulosic Fractions of banana biomass wastes

\begin{tabular}{lrrr}
\hline Lignocellulosic Fraction (wt. \%) & Peels & Leaves & Pseudostem \\
\hline Hemicellulose & $41.38 \pm 0.78$ & $23.46 \pm 0.54$ & $25.36 \pm 0.18$ \\
Cellulose & $9.9 \pm 0.14$ & $35.58 \pm 1.36$ & $38.48 \pm 1.05$ \\
Lignin & $8.9 \pm 1.28$ & $10.58 \pm 1.36$ & $5.77 \pm 0.16$ \\
Relative proportion & & & \\
$\frac{\text { Cellulose }}{\text { Lignin }}$ & 1.11 & 3.36 & 6.67 \\
$\frac{\text { Hemicellulose }}{\quad \text { Lignin }}$ & & & \\
\hline
\end{tabular}

The amount of lignin in lignocellulosic biomass depicts association with the biomass heating value (Saidur et al., 2011). Similarly from the banana biomasses, lignin influenced the HHV more than the cellulose and hemicellulose as can be noted from the calorific values in Table 4.

\subsection{Thermal Characteristics Results}

\subsubsection{Heating / Calorific Values}

The HHV is defined as the amount of heat discharged by burning a fuel with the water from its initial and condensed states while the LHV is generally determined based on vapour as the product. They outline the biomass fuel energy contents. Usually, the heating values for various fuels are described as either the gross calorific value (higher heating value, HHV) or the net calorific value (lower heating value, LHV) (Fernandes et al., 2013). The analyzed high heating values (HHV) and low heating values (LHV) of the banana biomasses are presented in Table 4. The HHV value was determined by the bomb calorimeter on dry basis while the LHV was calculated from the HHV and the proportion of hydrogen $(\mathrm{H})$ in the biomasses (Abdullah et al., 2014) using Equation 9:

$$
L H V_{d r y}=H H V_{d r y}-2.442 \times(8.936 H / 100) \quad M J / k g
$$


Table 4. HHV and LHV Calorific value of the banana biomass wastes

\begin{tabular}{lllll}
\hline Calorific Value $(\mathbf{M J} / \mathbf{k g})$ & Peels & Leaves & Pseudostem & $\boldsymbol{p}$-value \\
\hline High Heating Value & $16.15^{\mathrm{a}} \pm 0.13$ & $17.57^{\mathrm{b}} \pm 0.18$ & $15.04^{\mathrm{c}} \pm 0.17$ & 0.000 \\
Low Heating Value & $14.80^{\mathrm{a}} \pm 0.24$ & $16.16^{\mathrm{b}} \pm 0.16$ & $13.63^{\mathrm{c}} \pm 0.11$ & 0.001 \\
\hline
\end{tabular}

Note. ${ }^{\text {a }}$ Means not labeled with letter (a) are significantly different from control level mean

Similarly, according to Luo and Resende (2014), the HHV could be estimated from Equation 10 incooperating the individual elemental percentages from ultimate analysis data:

$$
H H V(M J / k g)=\% C \times 0.3578+\% H \times 1.1356+\% N \times 0.0594-\% O \times 0.0854-0.974
$$

Thus yielding the following approximated values: $15.00 \mathrm{MJ} / \mathrm{kg}, 16.57 \mathrm{MJ} / \mathrm{kg}$ and $14.09 \mathrm{MJ} / \mathrm{kg}$ for banana peels, leaves and pseudostem wastes, respectively. Generally, the HHV and LHV were higher in the leaves than the peels and pseudostem. This is because the leaves have high amounts of carbon and hydrogen with low oxygen thus a strong correlation with the heating value, that is, the higher the $\mathrm{C}$ and $\mathrm{H}$ contents the higher the heating value and vice versa (Saidur et al., 2011; Shah et al., 2012; Vardon et al., 2012 and Pighinelli et al., 2014). Compared to the HHV of other lignocellulosic biomasses: wheat straw (19 MJ/kg), olive husk $(16 \mathrm{MJ} / \mathrm{kg})$, pine $(17 \mathrm{MJ} / \mathrm{kg})$, douglas fir and ground coffee $(18.4$ and $22.7 \mathrm{MJ} / \mathrm{kg})$, corn stover $(19.2 \mathrm{MJ} / \mathrm{kg})$, sugarcane trash $(19.22 \mathrm{MJ} / \mathrm{kg}$ ), banana peels wastes are suitable feedstock for pyrolysis process and as a fuel source (Heikkinen et al., 2004; Yin, 2012; Shah et al., 2012; Fernandes et al., 2013; Pighinelli et al., 2014 and Soysa et al., 2015). This is also similar with work reported by Fernandes et al. (2013) who worked on semi-dried banana leaves $(19.8 \mathrm{MJ} / \mathrm{kg})$ and wet banana leaves $(5.5 \mathrm{MJ} / \mathrm{kg})$.

\subsubsection{Thermogravimetric Analysis (TGA)}

The outcomes of the thermogravimetric analysis of the pyrolytic properties of the banana wastes biomass peels for weight loss and rate of weight loss at the temperature range of $50-900^{\circ} \mathrm{C}$ are illustrated in Figure 2. Pyrolysis process occurred in three phases. In the first phase, dehydration of the biomass feed stock occurred in the temperatures between $50-200^{\circ} \mathrm{C}$. The weight reduction in this phase was due to the elimination of the sample moisture content (Chaiwong et al., 2013 and Biswas et al., 2016). However, there was thermal stability majorly due to the samples lower moisture content and the climatic and microbial exposure time (Fernandes et al., 2013). Consequently, in the second phase, devolatilization or thermal degradation of the biomass occurred. This was the reduction of the volatile matter content including the hemicellulose, cellulose and part of the lignin fractions and this was the cause of the drastic weight drop as illustrated in the graphs thus resulting in the least value in the DTA plot curve (Sait et al., 2012).

The average weight loss in this phase was approximately $60 \%$, and this was as a result of the release of volatile matter contents. At the heating rate of $15^{\circ} \mathrm{C} / \mathrm{min}$, thermal degradation of banana peels, leaves and pseudostem were initiated at approximately 150,170 and $200^{\circ} \mathrm{C}$, respectively, with the maximum devolatilization rate experienced between $450^{\circ} \mathrm{C}$ and $550^{\circ} \mathrm{C}$ (Maiaa et al., 2014; Abdullah et al., 2014 and Biswas et al., 2016). The final phase which was characterized with reduced weight loss was the solid decomposition stage and it occurred at temperatures between $600-900^{\circ} \mathrm{C}$ (Chaiwong et al., 2013). Similarly, the DTA curves also illustrates the degradation of the banana biomass in relation to their lignocellulosic constituents such as the cellulose, hemicelluloses and lignin (Sait et al., 2012). Figure 3 illustrates the comparisons between the TGA and DTA of three banana wastes feedstock (leaves, pseudostem and peels). The char residues left at the end of devolatilization was approximately $10 \%$ for the three samples. Generally, the pyrolysis behavior of the banana leaves, pseudostem and peels were similar. Therefore, as a result, the slow pyrolysis experiments can be carried out in the temperature range of $400-600^{\circ} \mathrm{C}$ as illustrated by the TGA highest devolatilization rate which was between $450-550^{\circ} \mathrm{C}$. Thermal stability of the banana wastes between $100-150^{\circ} \mathrm{C}$ and the thermal degradation between $450-550^{\circ} \mathrm{C}$ showed similarities with other plant biomasses. This was a strong indicator of banana wastes' potential for use as a renewable energy and pyrolysis feedstock. 


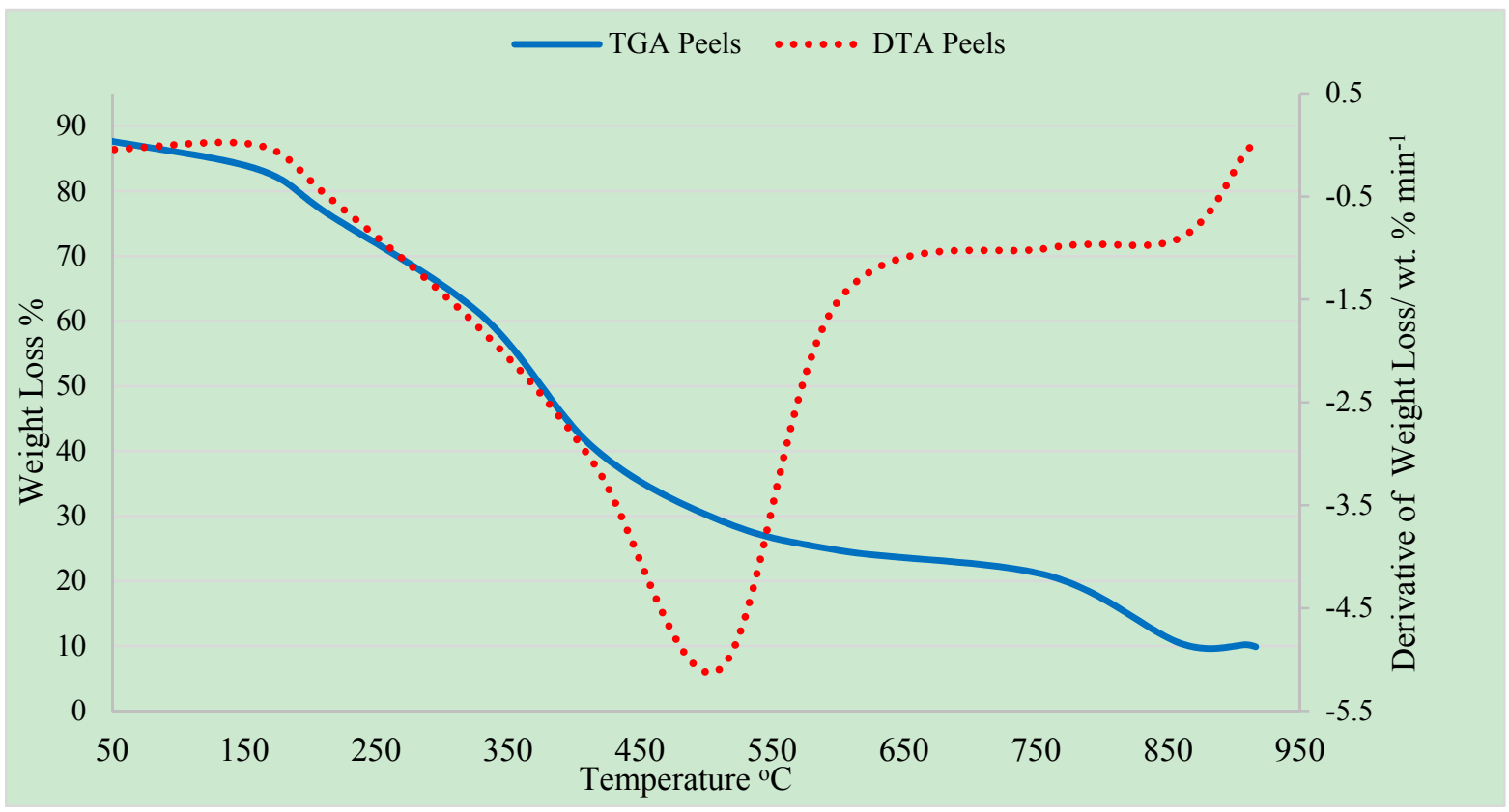

Figure 2. Thermogravimetric Analysis (TGA) and Differential Thermal analysis (DTA) plots for pyrolysis of Banana Peels

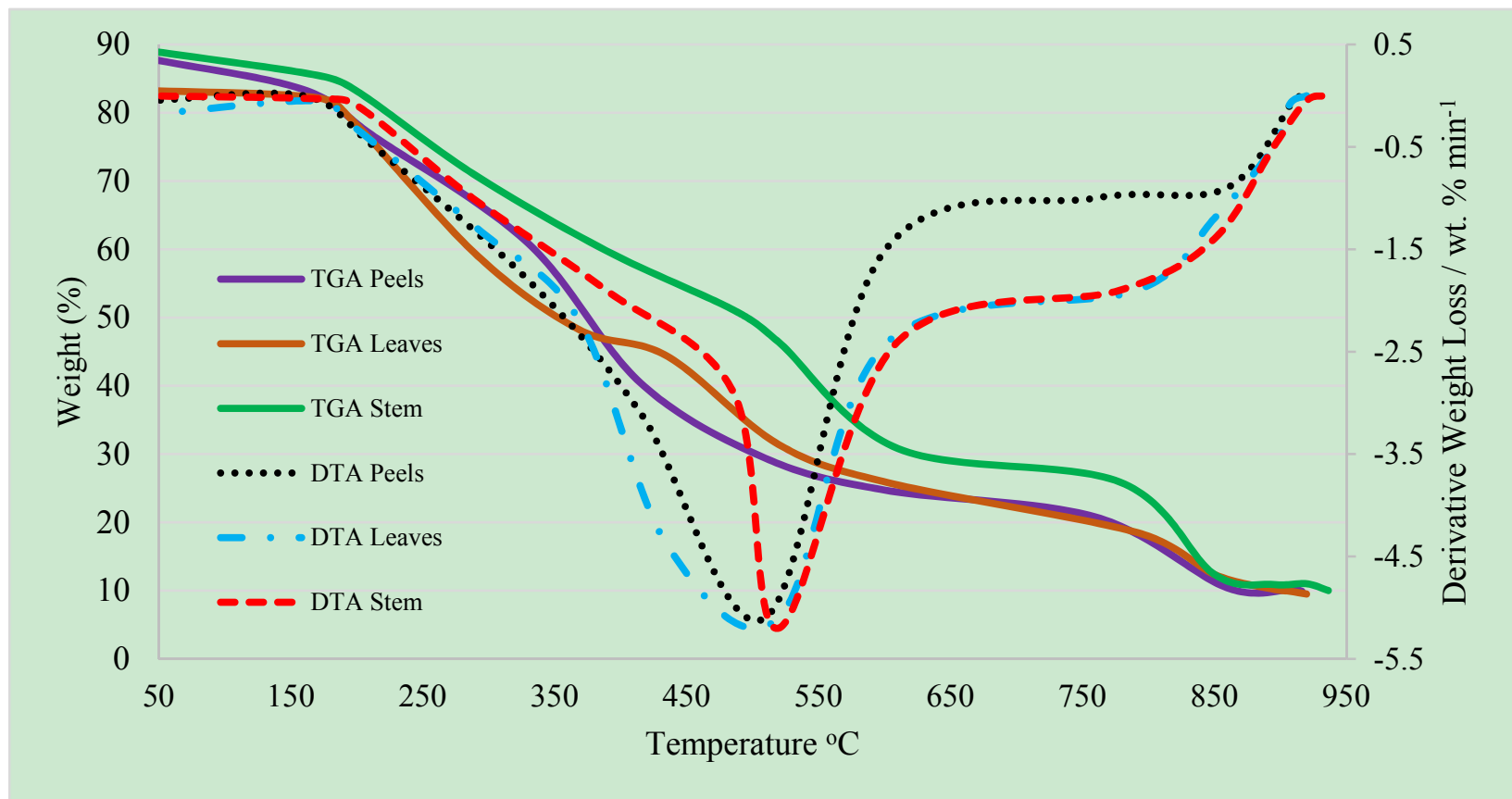

Figure 3. Thermogravimetric Analysis (TGA) and Differential Thermal analysis (DTA) plots for pyrolysis of banana peels, Leaves and Pseudostem

\section{Conclusions}

Characterization of biomass before the slow pyrolysis process is the backbone for establishing suitability for use of banana wastes to yield vinegar, tar and biochar. The banana peels biomass characterization results were comparable to other lignocellulosic biomasses reported in literature. The high levels of fixed carbon, volatile matter and ash contents were strong indicators that banana peels are adequate feedstock for pyrolysis work to yield value added bio-infrastructure products. The maximum weight degradation rate for the banana peels 
biomass occurred in the temperature range of $450-550^{\circ} \mathrm{C}$ which was taken as the slow pyrolysis regime. Similarly, the lignin, cellulose and hemicellulose fractions had significant correlation between the biomass heating values and the eventual chemical compounds present in vinegar and tar. In conclusion, the pyrolysis characteristics of the banana leaves, pseudostem and peels biomasses were generally comparable.

\section{Acknowledgements}

Special regards to Mobility for Enhancing Training of Engineering Graduates of Africa (METEGA) and RUFORUM for sponsoring of this research. Best regards to Makerere University Animal Science and Mechanical Engineering laboratories for their assistance in the biomass characterization.

\section{References}

Abdullah, N., Sulaiman, F., Miskam, M. A., \& Taib, R. M. (2014). Characterization of Banana ( Musa spp.) Pseudo-Stem and Fruit-Bunch-Stem as a Potential Renewable Energy Resource. International Journal of Biological, Veterinary, Agricultural and Food Engineering, 8(8), 712-716.

Biswas, B., Singh, R., Kumar, J., Khan, A. A., Krishna, B. B., \& Bhaskar, T. (2016). Slow pyrolysis of prot, alkali and dealkaline lignins for production of chemicals. Bioresource Technology, 1-8. https://doi.org/10.1016/j.biortech.2016.01.131

Chaiwong, K., Kiatsiriroat, T., Vorayos, N., \& Thararax, C. (2013). Study of bio-oil and bio-char production from algae by slow pyrolysis. Biomass and Bioenergy, 56, 600-606. https://doi.org/10.1016/j.biombioe.2013.05.035

Doumer, M. E., Arízaga, G. G. C., Silva, D. A. Da, Yamamoto, C., Novotny, E. H., Santos, J. M., ... Mangrich, A. S. (2015). Slow pyrolysis of different Brazilian waste biomasses as sources of soil conditioners and energy, and for environmental protection. Journal of Analytical and Applied Pyrolysis, 113, 434-443. https://doi.org/10.1016/j.jaap.2015.03.006

FAO. (2013). Food and Agriculture Organization of the United Stations. Retrieved July 4, 2015, from ftp://ftp.fao.org/docrep/fao/W7744E/W7744E00.pdf

Fernandes, E. R. K., Marangoni, C., Medeiros, S. H. W., Souza, O., Sellin, N., \& Industrial, Z. (2012). Slow Pyrolysis of Banana Culture Waste: Leaves and Pseudostem. In 3rd International Conference on Industrial and Hazardous waste management (pp. 1-8).

Fernandes, E. R. K., Marangoni, C., Souza, O., \& Sellin, N. (2013). Thermochemical characterization of banana leaves as a potential energy source. Energy Conversion and Management, 75, 603-608. https://doi.org/10.1016/j.enconman.2013.08.008

Heikkinen, J. M., Hordijk, J. C., De Jong, W., \& Spliethoff, H. (2004). Thermogravimetry as a tool to classify waste components to be used for energy generation. Journal of Analytical and Applied Pyrolysis, 71(2), 883-900. https://doi.org/10.1016/j.jaap.2003.12.001

Jourabchi, S. A., Gan, S., \& Ng, H. K. (2014). Pyrolysis of Jatropha curcas pressed cake for bio-oil production in a fixed-bed system. Energy Conversion and Management, 78, 518-526. https://doi.org/10.1016/j.enconman.2013.11.005

Luo, G., \& Resende, F. L. P. (2014). Fast pyrolysis of beetle-killed trees. Journal of Analytical and Applied Pyrolysis, 110, 100-107. https://doi.org/10.1016/j.jaap.2014.08.010

Maiaa, B. G. de O., Souzab, O., Marangonib, C., Hotzaa, D., Oliveiraa, A. P. N. de, \& Sellinb, N. (2014). Production and Characterization of Fuel Briquettes from Banana Leaves Waste. Chemical Engineering Transactions, 37, 439-444. https://doi.org/10.3303/CET1437074

Montoya, J. I., Valdés, C., Chejne, F., Gómez, C. a., Blanco, a., Marrugo, G., ... Acero, J. (2014). Bio-oil production from Colombian bagasse by fast pyrolysis in a fluidized bed: An experimental study. Journal of Analytical and Applied Pyrolysis, 112, 379-387. https://doi.org/10.1016/j.jaap.2014.11.007

Moore, A., Park, S., Segura, C., \& Carrier, M. (2015). Fast pyrolysis of lignin-coated radiata pine. Journal of Analytical and Applied Pyrolysis. https://doi.org/10.1016/j.jaap.2015.07.017

Okello, C., Pindozzi, S., Faugno, S., \& Boccia, L. (2013). Development of bioenergy technologies in Uganda: A review of progress. Renewable and Sustainable Energy Reviews, 18, 55-63. https://doi.org/10.1016/j.rser.2012.10.004

Omulo, G., Banadda, N., \& Kiggundu, N. (2015). Harnessing of banana ripening process for banana juice 
extraction in Uganda. African Journal of Food Science and Technology, 6(4), 108-117. https://doi.org/http:/dx.doi.org/10.14303/ajfst.2015.039

Pérez-Hidalgo, M., Guerra-Hernández, E., \& García-Villanova, B. (1997). Determination of insoluble dietary fiber compounds: Cellulose, hemicellulose and lignin in legumes. Ars Pharmaceutica, 38(4), 357-364.

Pighinelli, A. L. M. T., Boateng, A. a., Mullen, C. a., \& Elkasabi, Y. (2014). Evaluation of Brazilian biomasses as feedstocks for fuel production via fast pyrolysis. Energy for Sustainable Development, 21, 42-50. https://doi.org/10.1016/j.esd.2014.05.002

Plis, A., Lasek, J., Skawińska, A., \& Zuwała, J. (2015). Thermochemical and kinetic analysis of the pyrolysis process in Cladophora glomerata algae. Journal of Analytical and Applied Pyrolysis. https://doi.org/10.1016/j.jaap.2015.07.013

Saidur, R., Abdelaziz, E. a., Demirbas, a., Hossain, M. S., \& Mekhilef, S. (2011). A review on biomass as a fuel for boilers. Renewable and Sustainable Energy Reviews, 15(5), 2262-2289. https://doi.org/10.1016/j.rser.2011.02.015

Saikia, R., Chutia, R. S., Kataki, R., \& Pant, K. K. (2015). Perennial grass (Arundo donax L.) as a feedstock for thermo-chemical conversion to energy and materials. Bioresource Technology, 1-8. https://doi.org/10.1016/j.biortech.2015.01.089

Sait, H. H., Hussain, A., Salema, A. A., \& Ani, F. N. (2012). Pyrolysis and combustion kinetics of date palm biomass using thermogravimetric analysis. Bioresource Technology, 118, 382-389. https://doi.org/10.1016/j.biortech.2012.04.081

Selvarajoo, A., \& Hanson, S. (2014). Pyrolysis of Pineapple Peel: Effect of Temperature, Heating Rate and Residence Time on the Bio-char Yield. In Proceedings of the 2nd International Conference on Advances in Applied Science and Environmental Engineering - ASEE 2014 (pp. 24-28). https://doi.org/10.15224/978-1-63248-033-0-06

Shah, A., Darr, M. J., Dalluge, D., Medic, D., Webster, K., \& Brown, R. C. (2012). Physicochemical properties of bio-oil and biochar produced by fast pyrolysis of stored single-pass corn stover and cobs. Bioresource Technology, 125, 348-352. https://doi.org/10.1016/j.biortech.2012.09.061

Soetardji, J. P., Widjaja, C., Djojorahardjo, Y., Soetaredjo, F. E., \& Ismadji, S. (2014). Bio-oil from Jackfruit Peel Waste. Procedia Chemistry, 9, 158-164. https://doi.org/10.1016/j.proche.2014.05.019

Soysa, R., Choi, S. K., Jeong, Y. W., Kim, S. J., \& Choi, Y. S. (2015). Pyrolysis of Douglas fir and coffee ground and product biocrude-oil characteristics. Journal of Analytical and Applied Pyrolysis, 1-6. https://doi.org/10.1016/j.jaap.2015.07.002

UBoS. (2014). Uganda Bureau of Statistics. Statistical Abstract, 2014. Kampala, Uganda.

Van-Soest, P. J., \& Wine, R. H. (1968). Determination of lignin and cellulose in acid-detergent fiber with permanganate.No Title. Journal of the Association of Official Analytical Chemists, 51(1), 780-785.

Vardon, D. R., Sharma, B. K., Blazina, G. V, Rajagopalan, K., \& Strathmann, T. J. (2012). Thermochemical conversion of raw and defatted algal biomass via hydrothermal liquefaction and slow pyrolysis. Bioresource Technology, 109, 178-187. https://doi.org/10.1016/j.biortech.2012.01.008

$\mathrm{Xu}$, J., Wang, Z., \& Cheng, J. J. (2011). Bermuda grass as feedstock for biofuel production: A review. Bioresource Technology, 102(17), 7613-7620. https://doi.org/10.1016/j.biortech.2011.05.070

Yin, C. (2012). Microwave-assisted pyrolysis of biomass for liquid biofuels production. Bioresource Technology, 120, 273-284. https://doi.org/10.1016/j.biortech.2012.06.016

Yoder, J., Galinato, S., Granatstein, D., \& Garcia-Pérez, M. (2011). Economic tradeoff between biochar and bio-oil production via pyrolysis. Biomass and Bioenergy, 35(5), 1851-1862. https://doi.org/10.1016/j.biombioe.2011.01.026

\section{Copyrights}

Copyright for this article is retained by the author(s), with first publication rights granted to the journal.

This is an open-access article distributed under the terms and conditions of the Creative Commons Attribution license (http://creativecommons.org/licenses/by/4.0/). 